\title{
Silybin suppresses cell proliferation and induces apoptosis of multiple myeloma cells via the PI3K/Akt/mTOR signaling pathway
}

\author{
NAN FENG ${ }^{1}$, JIANMIN LUO ${ }^{1}$ and XIMIN GUO ${ }^{2}$ \\ ${ }^{1}$ Department of Hematology, The Second Hospital of Hebei Medical University, Shijiazhuan, Hebei 050000; \\ ${ }^{2}$ Academy of Military Medical Sciences of the Chinese PLA, Beijing 100850, P.R. China
}

Received January 10, 2015; Accepted October 21, 2015

DOI: $10.3892 / \mathrm{mmr} .2016 .4887$

\begin{abstract}
Silybin is a biologically active component extracted from the seeds of Silybum marianum, which has been shown to have inhibitory effects on prostate, skin, bladder, lung and colon cancer cells, in addition to its efficacy in the treatment of liver diseases, including hepatitis and cirrhosis. The aim of the present study was to investigate whether silybin suppresses the proliferation and induces apoptosis of multiple myeloma (MM) cells and to elucidate its molecular targets. The proliferative and apoptotic rates of the U266 MM cell line were assessed using MTT and flow-cytometric assays, respectively. Western blot analysis was used to assess the protein levels of phosphoinositide-3 kinase (PI3K), phosphorylated (p)-Akt and p-mammalian target of rapamycin (mTOR) in U266 cells. In addition, PI3K inhibitor LY294002 or activator insulin-like growth factor 1 were used to investigate the involvement of the PI3K/Akt-mTOR signaling pathway in the effect of silybin on U266 cells. The results revealed that silybin restrained the proliferation and enhanced the apoptosis of U266 cells. Furthermore, silybin inhibited the protein expression of PI3K, p-Akt and p-mTOR in U266 cells. Of note, inhibition of PI3K facilitated silybin-mediated reduction of mTOR activation, cell proliferation and induction of apoptosis in U266 cells, while activation of PI3K attenuated the effects of silybin. In conclusion, silybin suppressed cell proliferation and promoted apoptosis of U266 cells via PI3K/Akt-mTOR signaling pathways.
\end{abstract}

Correspondence to: Mr. Jianmin Luo, Department of Hematology, The Second Hospital of Hebei Medical University, 215 Peace Road, Shijiazhuan, Hebei 050000, P.R. China

E-mail: jianminluohb@163.com

Mr. Ximin Guo, Academy of Military Medical Sciences of the Chinese PLA, 27 Taiping Road, Haidian, Beijing 100850, P.R. China E-mail: ximinguobj@163.com

Key words: silybin, multiple myeloma, phosphoinositide-3 kinase/Akt, mammalian target of rapamycin

\section{Introduction}

Multiple myeloma (MM) is a malignant tumor type originating from B cells and is characterized by the increase of abnormal plasma cells that generate monoclonal immunoglobulin as well as malignant proliferation in the bone marrow, which cause fractures and bone marrow failure, resulting in severe clinical symptoms (1). If left untreated, the median survival time of advanced MM patients is only six months, while it is not more than three years in patients receiving traditional chemotherapy; only $25 \%$ of patients survive for more than five years (2). Therefore, MM is currently considered to be an incurable disease, which urgently requires novel approaches to improve the prognosis of patients (3).

The phosphoinositide-3 kinase (PI3K)/Akt/mammalian target of rapamycin (mTOR) pathway is an important signaling pathway that affects cellular energy metabolism, cell size, cell cycle, cell proliferation as well as cell survival and apoptosis, and is closely linked to other important signal transduction pathways (4). Therapies targeting the PI3K/AKT/mTOR signaling pathway in combination with other drugs represent promising treatment approaches. The PI3K/AKT/mTOR pathway has important roles in the survival and growth of MM cells and has been shown to be the target of natural products with anti-MM efficacy (5).

Silybin (Fig. 1) is a biologically active component extracted from the seeds of milk thistle, Silybum marianum, and its derivatives have been demonstrated to exhibit marked anti-cancer activity (6). In-vitro studies have shown that silybin inhibits androgen-dependent and -independent prostate cancer as well as skin, bladder, lung, colon, breast, ovarian, renal, liver, cervical and tongue cancer (7-9). However, the anti-cancer effects of silybin on MM cells and its underlying mechanisms of action have not yet been fully elucidated. The present study aimed to assess the ability of silybin to inhibit the growth and induce apoptosis of human $\mathrm{MM}$ cells in vitro. In addition, the possible involvement of the PI3K/Akt/mTOR signaling pathway in the anti-MM effects of silybin was investigated. The present study suggested that silybin is a promising candidate for the clinical treatment of MM which exerts its effects via the PI3K/Akt/mTOR pathway. 


\section{Materials and methods}

Reagents. RPMI-1640 and fetal bovine serum (FBS) were obtained from Sigma-Aldrich (St. Louis, MO, USA). 3-(4,5-dimethylthylthiazol-2-yl)-2,5-diphenyl tetrazolium bromide (MTT) and a TRIzol reagent kit were purchased from Invitrogen (Thermo Fisher Scientific, Waltham, MA, USA). A Cell Apoptosis Detection kit was obtained from BD Biosciences (Franklin Lakes, NJ, USA). A bicinchoninic acid (BCA) Protein Assay kit was purchased from Beyotime Institute of Biotechnology (Haimen, China).

Cell culture and cell viability assay. The U266 human multiple myeloma cell line was acquired from the Shanghai Cell Bank of the Chinese Academy of Sciences (Shanghai, China) and cultured in (RPMI-1640) with 10\% FBS, $100 \mathrm{U} / \mathrm{ml}$ penicillin and $100 \mathrm{mg} / \mathrm{ml}$ streptomycin (Amresco, LLC, Solon, $\mathrm{OH}$, USA) at $37^{\circ} \mathrm{C}$ in a humidified atmosphere containing $5 \%$ $\mathrm{CO}_{2}$. The cell viability assay was performed according to the protocol of a previous study (10). Following seeding of cells into 96-well plates at $1 \times 10^{4} /$ well and an overnight incubation for attachment, cells were incubated with silybin $(50,100$ or $200 \mu \mathrm{M}$; Sigma-Aldrich; >98\% purity) for 12,24 , or $48 \mathrm{~h}$. A total of $20 \mu \mathrm{l}$ MTT solution $(5 \mathrm{mg} / \mathrm{ml})$ was then added to each well, followed by culture for another $4 \mathrm{~h}$ at $37^{\circ} \mathrm{C}$. Subsequently, the media were removed and $200 \mu 1$ dimethylsulfoxide (Amresco, LLC) was added to each well. Following agitation for $20 \mathrm{~min}$, the absorbance of each well was measured using an ELx800 microplate absorbance reader (Bio-Tek Instruments, Winooski, VT, USA) at $\lambda=570 \mathrm{~nm}$.

Flow cytometry. Following incubation of U266 cells seeded into six-well plates at $1 \times 10^{6} /$ well with silybin $(50,100$ or $200 \mu \mathrm{M}$ for $24 \mathrm{~h}$ ), cells were harvested and centrifuged at $1,000 \times \mathrm{g}$ for $5 \mathrm{~min}$ at $4^{\circ} \mathrm{C}$. Subsequent to two washes with ice-cold phosphate-buffered saline, cell suspensions were incubated with $10 \mu \mathrm{l}$ fluorescein-conjugated Annexin V (100 mg/ml; BD Biosciences) for $30 \mathrm{~min}$ in the dark. $5 \mu \mathrm{l}$ propidium iodide (PI; $100 \mathrm{mg} / \mathrm{ml}$; BD Biosciences) was then added and cells were incubated for a further $30 \mathrm{~min}$ in the dark on ice. Flow cytometry (FACSCalibur; BD Biosciences) was used to determine the apoptotic rate.

Western blot analysis. Following treatment of U266 cells with silybin as described above, cells were lysed and the protein contents were determined using the BCA Protein Assay kit according to the manufacturer's instructions. Equal amounts of protein were loaded into each lane and separated by $10 \%$ sodium dodecyl sulfate polyacrylamide gel electrophoresis. Subsequently, proteins were transferred onto a polyvinylidene difluoride membrane at $4^{\circ} \mathrm{C}$ for $2 \mathrm{~h}$. The membranes were blocked in $5 \%$ non-fat milk for $2 \mathrm{~h}$ and then incubated with anti-PI3K (1:1,000; cat. no. SAB1300969; Sigma-Aldrich) anti-phosphorylated (p)-Akt (1:1,000; cat. no. SAB4301414; Sigma-Aldrich), anti-p-mTOR (1:2,000; cat. no. SAB4301415; Sigma-Aldrich) and $\beta$-actin (1:1,000; cat. no. AA128; Beyotime Institute of Biotechnology) antibodies overnight at $4^{\circ} \mathrm{C}$ with agitation. Membranes were then incubated with horseradish peroxidase-conjugated goat anti-mouse secondary antibody (1:3,000; cat. no. PA112; Tiangen, Beijing, China) for $2 \mathrm{~h}$ at room<smiles>COc1cc([C@H]2Oc3cc([C@H]4Oc5cc(O)cc(O)c5C(=O)[C@H]4O)ccc3O[C@H]2CO)ccc1O</smiles>

Figure 1. Chemical structure of silybin.

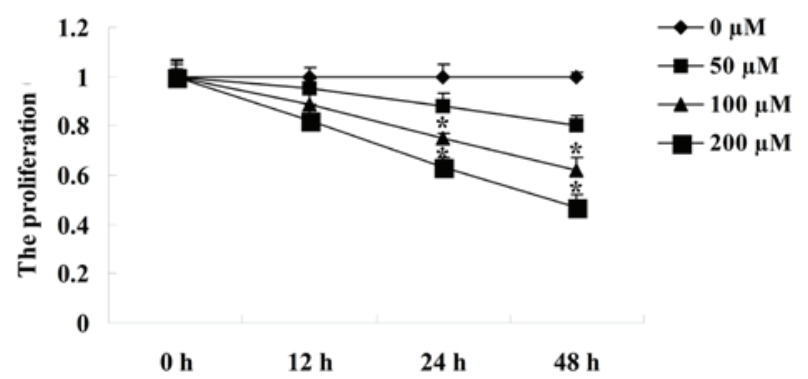

Figure 2. Silybin inhibits the proliferation of U266 cells. Values are expressed as the mean \pm standard deviation. ${ }^{*} \mathrm{P}<0.01$ vs. $0 \mu \mathrm{M}$ silybin-treated group.

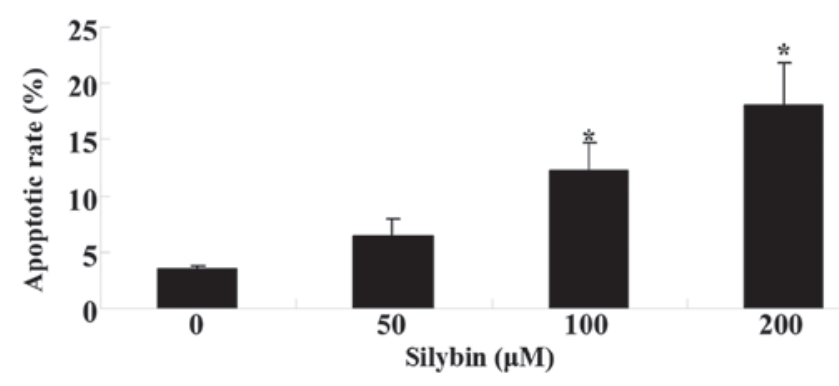

Figure 3. Silybin induces cellular apoptosis of U266 cells following $24 \mathrm{~h}$ of incubation. Values are expressed as the mean \pm standard deviation. ${ }^{*} \mathrm{P}<0.01$ vs. $0 \mu \mathrm{M}$ silybin-treated group.

temperature. After washing three times with Tris-buffered saline with $0.1 \%$ Tween 20 for $5 \mathrm{~min}$, membranes were developed using enhanced chemiluminescence (Tiangen), resolved using a gel analysis system (Pierce Biotechnology, Inc., Rockford, IL, USA) and exposed to X-ray film (Kodak, Rochester, NY, USA).

Statistical analysis. Statistical analyses were performed using SPSS 19.0 software (SPSS, Inc., Chicago, IL, USA). Values are expressed as the mean \pm standard deviation. $\mathrm{P}<0.05$ was considered to indicate a statistically significant difference.

\section{Results}

Silybin inhibits the proliferation of U266 cells. The MTT assay revealed that following incubation with 100 or $200 \mu \mathrm{M}$ silybin for 24 or $48 \mathrm{~h}$, the proliferation of U266 cells was significantly inhibited compared with that of the untreated cells $(\mathrm{P}<0.05)$. Silybin inhibited the proliferation of U266 cells in a dose- and time-dependent manner (Fig. 2).

Silybin induces apoptosis of U266 cells. To determine whether silybin induces apoptosis of U266 cells flow-cytometric analysis following staining with Annexin V/PI was performed. 
A

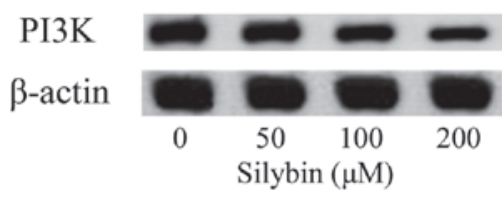

C

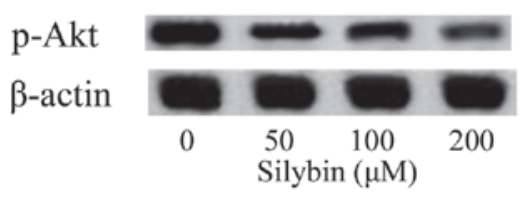

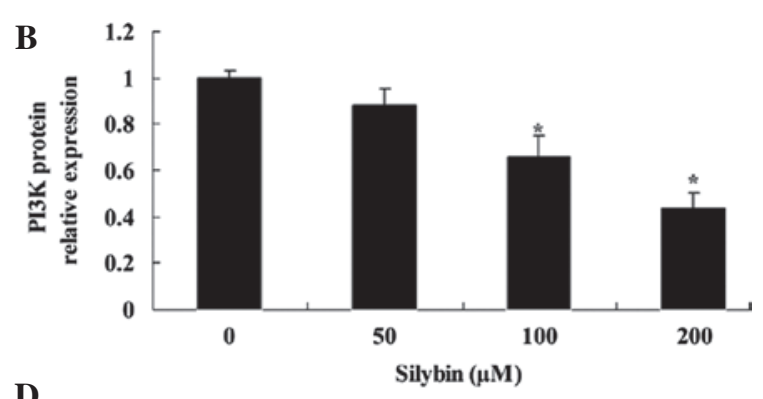

D

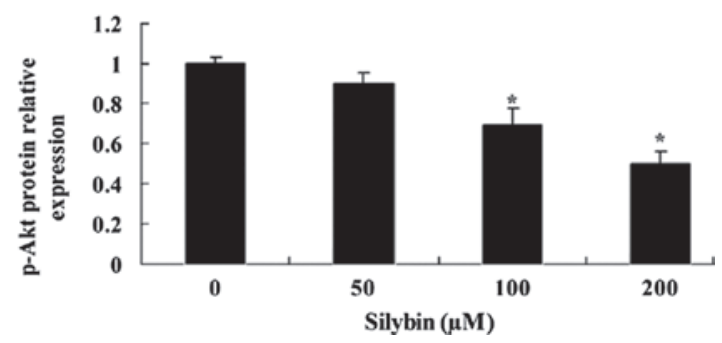

Figure 4. Silybin suppresses the PI3K/Akt pathway in U266 cells. (A) Representative western blot of PI3K and (B) quantified expression levels obtained by densitometric analysis with normalization to $\beta$-actin. (C) Representative western blot of p-Akt and (D) quantified expression levels obtained by densitometric analysis with normalization to $\beta$-actin. Values are expressed as the mean \pm standard deviation. ${ }^{*} \mathrm{P}<0.01$, compared with $0 \mu \mathrm{M}$ silybin-treated group. p-Akt, phosphorylated Akt.
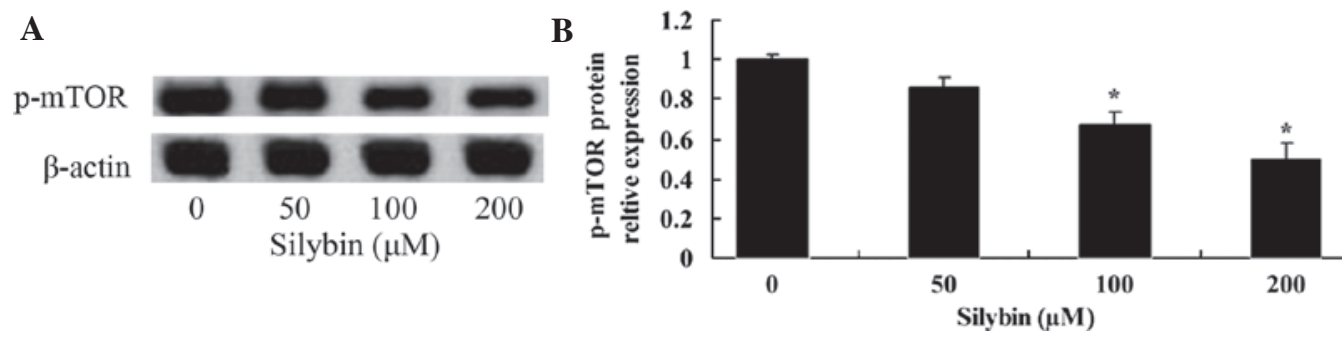

Figure 5. Silybin suppresses mTOR signaling in U266 cells. (A) Representative western blot of p-mTor and (B) quantified expression levels obtained by densitometric analysis with normalization to $\beta$-actin. Values are expressed as the mean \pm standard deviation. ${ }^{*} \mathrm{P}<0.01$, compared with $0 \mu \mathrm{M}$ silybin-treated group. p-mTor, phosphorylated mammalian target of rapamycin.

Silybin (100 or $200 \mu \mathrm{M})$ significantly increased the apoptotic rate of $\mathrm{U} 266$ cells following for 24 of incubation. The induction of U266-cell apoptosis by silybin was dose-dependent (Fig. 3).

Silybin suppresses PI3K/Akt in U266 cells. To analyze the underlying molecular mechanisms of silybin-mediated induction of U266-cell apoptosis, proteins of the PI3K/Akt signaling pathway were assessed using western blot analysis. After a 24-h incubation with silybin (100 or $200 \mu \mathrm{M})$, protein levels of PI3K and p-Akt in U266 cells were significantly decreased (Fig. 4A-D). Furthermore, the effects of silybin on PI3K and p-Akt were in a dose-dependent. These results indicated that silybin may induce cellular apoptosis of U266 cells via inhibiting the PI3K/Akt signaling pathway.

Silybin suppresses mTOR in U266 cells. The present study assessed the involvement of the mTOR signaling pathway in the mechanism of action of silybin by using western blot analysis. Following $24 \mathrm{~h}$ of incubation, silybin $(100$ or $200 \mu \mathrm{M})$ significantly reduced the levels of p-mTOR (Fig. 5A and B). Furthermore, the effect of silybin on the activation of mTOR were dose-dependent. These results indicated that the induction of U266-cell apoptosis by silybin may be mediated via inhibiting PI3K/Akt/mTOR signaling.
Inhibition of the PI3K/Akt pathway enhances the potency of silybin in U266 cells. To confirm the involvement of the PI3K/Akt pathway in the effects of silybin on U266 cells, they were co-treated with silybin and PI3K inhibitor LY294002 $(3 \mu \mathrm{M})$ for $24 \mathrm{~h}$. The reduction in cell proliferation and the induction of apoptosis by silybin $(100 \mu \mathrm{M})$ were enhanced by the PI3K inhibitor when compared to treatment with silybin alone (Fig. 6A and B). These results indicated that the mechanism of action of silybin in U266 cells involved the inhibition of the PI3K/Akt pathway.

Inhibition of PI3K/Akt enhances silybin-induced reduction of mTOR activity in U266 cells. To further assess whether inhibition of PI3K/AKT enhanced silybin-induced apoptosis through modulation of mTOR activity of U266 cells, they were co-incubated with silybin and PI3K inhibitor LY294002 for $24 \mathrm{~h}$. The silybin-induced reduction of p-mTOR levels was enhanced by treatment with PI3K inhibitor (Fig. 7A and B). These results indicated that the apoptotic effects of silybin on U266 cells may be mediated via PI3K/AKT/mTOR signaling.

Activation of the PIBK/AKT pathway reduces the potency of silybin in U266 cells. To further investigate the involvement of the PI3K/AKT pathway in the anti-MM activity of silybin, 

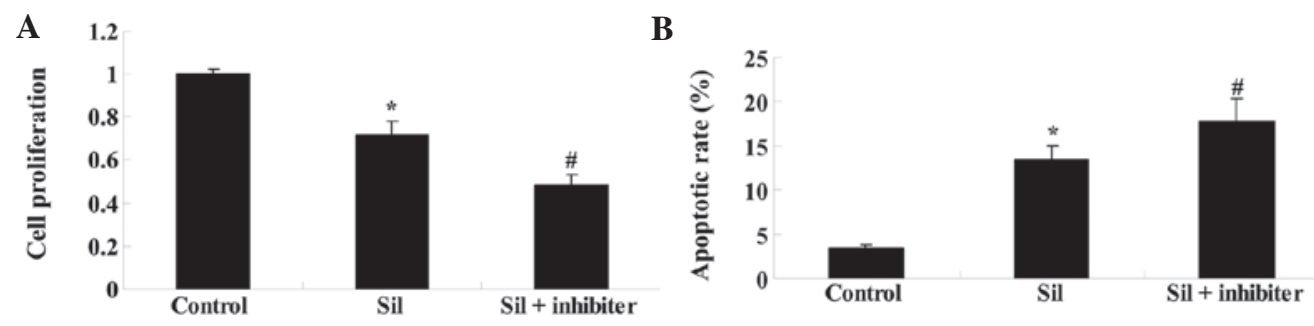

Figure 6. Inhibition of the PI3K/AKT pathway enhances silybin-induced (A) inhibition of cell proliferation and (B) induction of apoptosis of U266 cells. Values are expressed as the mean \pm standard deviation. ${ }^{*} \mathrm{P}<0.01$ compared with control group, ${ }^{~} \mathrm{P}<0.01$, compared with Sil group. Sil, silybin; inhib, PI3K inhibitor LY294002; PI3K, phosphoinositide-3 kinase.
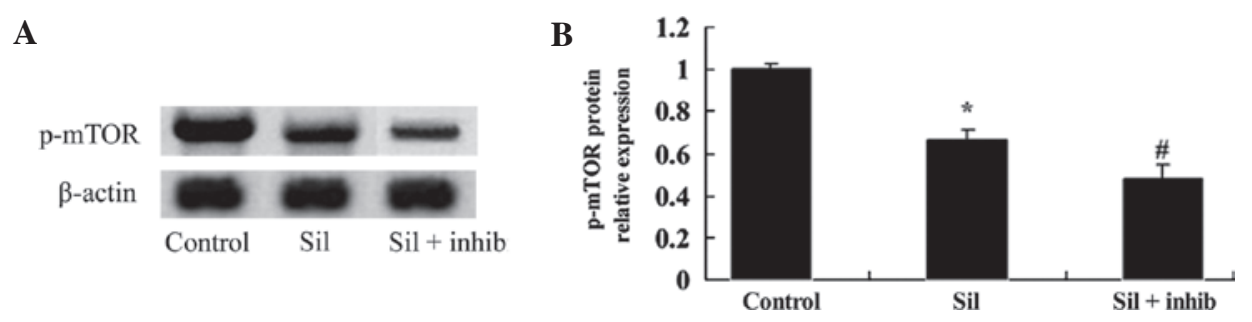

Figure 7. Inhibition of PI3K/AKT enhances silybin-induced inhibition of mTOR activity in U266 cells. (A) Representative western blot of p-mTor and (B) quantified expression levels of p-mTor in U266 cells treated with silybin with or without PI3K inhibitor obtained by densitometric analysis with normalization to $\beta$-actin. Values are expressed as the mean \pm standard deviation. ${ }^{*} \mathrm{P}<0.01$ compared with control group, ${ }^{\text {" }} \mathrm{P}<0.01$, compared with Sil group. Sil, silybin; inhib, PI3K inhibitor LY294002; PI3K, phosphoinositide-3 kinase; p-mTor, phosphorylated mammalian target of rapamycin.

A

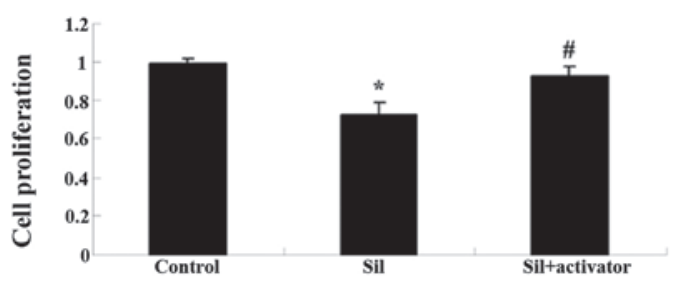

B

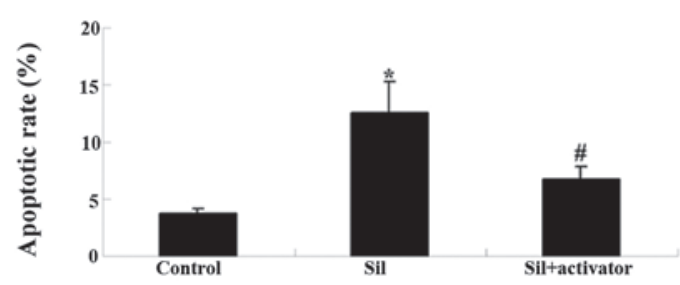

Figure 8. Activation of the PI3K/AKT pathway reduces silybin-mediated (A) inhibition of cell proliferation and (B) induction of apoptosis of U266 cells. Values are expressed as the mean \pm standard deviation. ${ }^{*} \mathrm{P}<0.01$ compared with control group, ${ }^{\#} \mathrm{P}<0.01$, compared with Sil group. Sil, silybin; activator, insulin-like growth factor-1; PI3K, phosphoinositide-3 kinase.
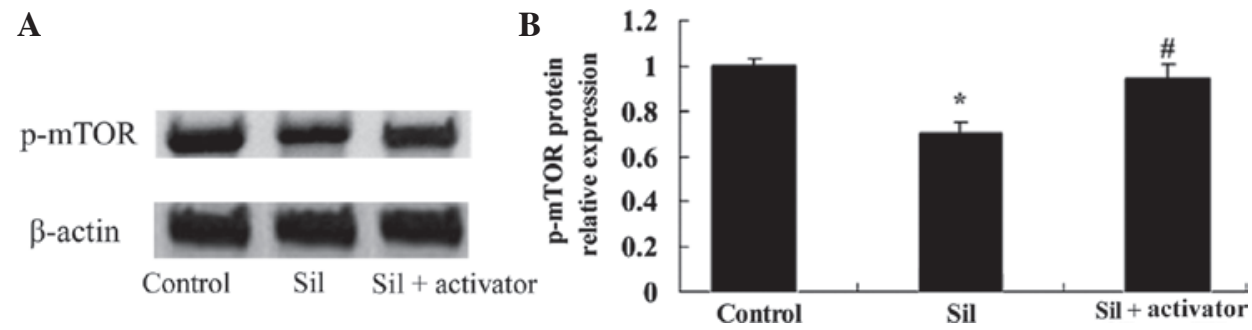

Figure 9. Activation of the PI3K/AKT pathway reduces silybin-induced inhibition of mTOR activity in U266 cells. (A) Representative western blot of p-mTor and (B) quantified expression levels of p-mTor in U266 cells treated with silybin with or without PI3K activator obtained by densitometric analysis with normalization to $\beta$-actin. Activation of the PI3K/AKT pathway significantly attenuated the inhibition of mTOR protein expression. Values are expressed as the mean \pm standard deviation. "P<0.01 compared with control group, ${ }^{~} \mathrm{P}<0.01$ compared with Sil group. Sil, silybin; activator, insulin-like growth factor-1; PI3K, phosphoinositide-3 kinase; p-mTor, phosphorylated mammalian target of rapamycin.

U266 cells were co-treated with silybin and PI3K activator insulin-like growth factor-1 (IGF-1; $10 \mu \mathrm{M}$ ) for $24 \mathrm{~h}$. The anti-proliferative and apoptotic effects of silybin on U266 cells were reversed by the PI3K inhibitor (Fig. 8A and B).

Activation of the PI3K/AKT pathway attenuates silybin-induced reduction of mTOR activity in $U 266$ cells. To further assess the effects of PI3K/AKT pathway activation on silybin-induced inhibition of mTOR activity, U266 cells were co-treated with silybin and PI3K activator IGF-1 $(10 \mu \mathrm{M})$ for $24 \mathrm{~h}$. The silybin-induced reduction of p-mTOR was attenuated by the PI3K activator (Fig. 9A and B), which further indicated the involvement of the PI3K/Akt/mTOR pathway in the mechanism of action of silybin. 


\section{Discussion}

MM is a neoplastic condition featuring malignant plasma cells, whose main clinical manifestations include hypergammaglobulinemia, renal insufficiency, bone damage and pancytopenia (11). In spite of MM currently being considered to be incurable, significant progress has recently been made in clinical treatments, including the application of thalidomide, proteasome inhibitors and bone marrow transplantation, which, however, has not significantly increased the survival of MM patients $(12,13)$. Therefore, current research focuses on the discovery of novel treatments for MM. Recent studies have indicated that silybin exhibits marked anti-tumor activity and inhibits the growth of human hepatocellular carcinoma $(10,14)$. Previous studies by our group reported that silybin inhibited the growth and induced apoptosis of human MM cells in a dose-dependent manner. Thus, it was required to explore the mechanisms involved in the anti-cancer effects of silybin on MM cells and to assess its potential use in the clinic.

The PI3K/Akt pathway is a vital regulatory pathway involved in cell growth, proliferation and differentiation, while the overexpression of PI3K is a crucial step during carcinogenesis. PI3K is able to activate cyclin-dependent-kinase-4 (CDK4) as well as CDK2, which mediates the transition of cells into S-phase to induce DNA synthesis (15). Furthermore, PI3K controls the expression of $\mathrm{p} 27$, which is a negative regulator of the cell cycle. PI3K/Akt signaling can be inactivated through phosphorylation of sites Ser280 of checkpoint kinase 1, and PI3K/Akt can directly activate CDK1, which facilitates G2/M-phase transition (16). In this context, the findings of the present study indicated that silybin inhibits cell proliferation and induces apoptosis through suppression of the PI3K-Akt signaling pathway. In consistency with this, García-Maceira and Mateo (17) showed that silybin inhibited human cervical cancer as well as hepatoma cells through the $\mathrm{PI} 3 \mathrm{~K} / \mathrm{Akt} / \mathrm{mTOR}$ signaling pathway. Zhang et al (18) reported that silybin ameliorated steatosis and insulin resistance during non-alcoholic fatty liver disease development via the PI3K/Akt pathway. The results of the present study indicated that silybin significantly reduced PI3K and p-Akt protein levels in U266 cells in a dose-dependent manner.

mTOR is a protein kinase associated with the PI3K/Akt pathway, which can enhance mRNA transcription and translation through phosphorylative activation of proteins associated with mRNA translation (19). Akt activates mTOR by phosphorylating Ser2448 sites of mTOR to enhance the efficiency of mRNA translation, thereby increasing the expression of proteins associated with cell growth and differentiation, and accelerating tumorigenesis (20). The present study revealed that silybin treatment reduced the protein levels of p-mTOR in U266 cells in a dose-dependent manner. Raina et al (21) suggested that silybin restrained the proliferation of colorectal cancer cells through inhibiting PIK3CA/Akt-mTOR. Lin et al (22) reported that silybin inhibits age-associated macular degeneration of the hypoxia-dependent type via PI3K/Akt/mTOR.

Activated PI3K/Akt may further activate its downstream molecule mTOR through tuberous sclerosis $1 / 2$ (23). Due to the high homology of the mTOR carboxy terminus and the PI3K catalytic domain, mTOR is considered to be a family member of PI3K-associated protein kinases. Upon activation, mTOR can phosphorylate its two downstream molecules, namely translation-inhibition molecule EIF-4E binding protein 1 (4E-BP1) and ribosomal protein p70S6K. As 4E-BP1 is inactivated through phosphorylation, its ability to bind to EIF-4E is lost and results in the dissociation of the complex and the combination of EIF-4E with other translation initiation factors to induce protein translation (24). Following phosphorylative activation of p70S6K, protein synthesis is enhanced. Therefore, $\mathrm{PI} 3 \mathrm{~K} / \mathrm{Akt} / \mathrm{mTOR}$ is considered to be the main signal-regulating pathway of protein synthesis and is involved in the regulation of cell proliferation, differentiation and migration (11). Of note, in the present study, inhibition of PI3K enhanced the potency of silybin to reduce cell proliferation and induce apoptosis, and reduced the protein levels of p-mTOR in U266 cells. Conversely, activation of $\mathrm{PI} 3 \mathrm{~K}$ reduced the anti-proliferative and apoptotic effects of silybin as well as the reduction of p-mTOR levels in U266 cells. The results of the present study were consistent with those of previous studies. For instance, Lin et al (22) reported that silybin inhibited age-associated macular degeneration of the hypoxia-dependent type via PI3K/Akt/mTOR. Furthermore, Wang et al (25) showed that silybin exerted effects against experimental ischemic stroke, which may have been based on its anti-inflammatory effects mediated through the activation of Akt/mTOR signaling.

In conclusion, the present study showed that silybin suppressed cell proliferation and induced apoptosis of human MM cells. Furthermore, inhibition of PI3K/Akt/mTOR signaling pathways sensitized human MM cells to silybin treatment. Therefore, silybin is a promising candidate for the treatment of MM, and inhibition of the PI3K/Akt/mTOR signaling pathway appears to be an effective strategy for the enhancement of its efficacy.

\section{References}

1. García-Escobar I, Parrilla L, Ortega LM, Castellanos D, Pallarés MA and Cortés-Funés H: Clinical experience with plerixafor as a mobilization regimen for autologous peripheral blood stem cell transplantation in patients with refractory germ cell tumors. Mol Clin Oncol 2: 923-926, 2014.

2. Yang G, Geng C, Li Y, Liu A and Chen W: Multiple myeloma with extramedullary plasmacytoma invading the skin and eyeballs following autologous stem cell transplantation: A case report. Exp Ther Med 6: 883-886, 2013.

3. Yang LJ, Chen Y, He J, Yi S, Wen L, Zhao S and Cui GH: Effects of gambogic acid on the activation of caspase-3 and downregulation of SIRT1 in RPMI-8226 multiple myeloma cells via the accumulation of ROS. Oncol Lett 3: 1159-1165, 2012.

4. Kwon SJ, Lee JH, Moon KD, Jeong IY, Yee ST, Lee MK and Seo KI: Isoegomaketone induces apoptosis in SK-MEL-2 human melanoma cells through mitochondrial apoptotic pathway via activating the PI3K/Akt pathway. Int J Oncol 45: 1969-1976, 2014.

5. Yang Y, Zhou X, Xiao M, Hong Z, Gong Q, Jiang L and Zhou J: Discovery of chrysoeriol, a PI3K-akt-mTOR pathway inhibitor with potent antitumor activity against human multiple myeloma cells in vitro. J Huazhong Univ Sci Technolog Med Sci 30: 734-740, 2010.

6. Agarwal C, Wadhwa R, Deep G, Biedermann D, Gažák R, Křen V and Agarwal R: Anti-cancer efficacy of silybin derivatives-a structure-activity relationship. PLoS One 8: e60074, 2013.

7. Tan C, Xu X, Shang Y, Fu X, Xia G and Yang H: A novel approach for the efficient extraction of silybin from milk thistle fruits. Pharmacogn Mag 10: 536-540, 2014.

8. Gándara L, Sandes E, Di Venosa G, Prack McCormick B, Rodriguez L, Mamone L, Batlle A, Eiján AM and Casas A: The natural flavonoid silybin improves the response to photodynamic therapy of bladder cancer cells. J Photochem Photobiol B 133: 55-64, 2014. 
9. Mahmoodi N, Motamed N and Paylakhi SH: The comparison of the effects of silybin and silybin-phosphatidylcholine on viability and ESR expression in human breast cancer T47D cell line. Cell J16: 299-308, 2014.

10. Zhang S, Yang Y, Liang Z, Duan W, Yang J, Yan J, Wang N, Feng W, Ding M, Nie Y and Jin Z: Silybin-mediated inhibition of notch signaling exerts antitumor activity in human hepatocellular carcinoma cells. PLoS One 8: e83699, 2013.

11. Rui M, Huang Z, Liu Y, Wang Z, Liu R, Fu J and Huang H: Rosiglitazone suppresses angiogenesis in multiple myeloma via downregulation of hypoxia-inducible factor- $1 \alpha$ and insulin-like growth factor-1 mRNA expression. Mol Med Rep 10: 2137-2143, 2014.

12. Lin M, Zhu J, Shen H and Huang J: Gastrointestinal bleeding as an initial manifestation in asymptomatic multiple myeloma: A case report and review of the literature. Oncol Lett 5: 218-220, 2013.

13. Kabir AL, Rahman MJ, Begum M, Dipta TF, Baqui MN, Aziz A, Rahman F, Debnath RC and Habib MA: Response of vincristine, melphalan, cyclophosphamide and prednisolone in refractory multiple myeloma. Mymensingh Med J 21: 114-119, 2012.

14. Siegel AB, Narayan R, Rodriguez R, Goyal A, Jacobson JS, Kelly K, Ladas E, Lunghofer PJ, Hansen RJ, Gustafson DL, et al: A phase I dose-finding study of silybin phosphatidylcholine (milk thistle) in patients with advanced hepatocellular carcinoma. Integr Cancer Ther 13: 46-53, 2014.

15. Wang L, Wu J, Lu J, Ma R, Sun D and Tang J: Regulation of the cell cycle and PI3K/akt/mTOR signaling pathway by tanshinone I in human breast cancer cell lines. Mol Med Rep 11: 931-939, 2015.

16. Wang W, Ren F, Wu Q, Jiang D, Li H and Shi H: MicroRNA-497 suppresses angiogenesis by targeting vascular endothelial growth factor A through the PI3K/AKT and MAPK/ERK pathways in ovarian cancer. Oncol Rep 32: 2127-2133, 2014.

17. García-Maceira $P$ and Mateo J: Silibinin inhibits hypoxia-inducible factor-1alpha and mTOR/p70S6K/4E-BP1 signalling pathway in human cervical and hepatoma cancer cells: Implications for anticancer therapy. Oncogene 28: 313-324, 2009.
18. Zhang Y, Hai J, Cao M, Zhang Y, Pei S, Wang J and Zhang Q: Silibinin ameliorates steatosis and insulin resistance during non-alcoholic fatty liver disease development partly through targeting IRS-1/PI3K/akt pathway. Int Immunopharmacol 17: 714-720, 2013.

19. Gong G, Hu L, Liu Y, Bai S, Dai X, Yin L, Sun Y, Wang X and Hou L: Upregulation of HIF-1 $\alpha$ protein induces mitochondrial autophagy in primary cortical cell cultures through the inhibition of the mTOR pathway. Int J Mol Med 34: 1133-1140, 2014.

20. Chang Z, Shi G, Jin J, Guo H, Guo X, Luo F, Song Y and Jia X: Dual PI3K/mTOR inhibitor NVP-BEZ235-induced apoptosis of hepatocellular carcinoma cell lines is enhanced by inhibitors of autophagy. Int J Mol Med 31: 1449-1456, 2013.

21. Raina K, Agarwal C, Wadhwa R, Serkova NJ and Agarwal R: Energy deprivation by silibinin in colorectal cancer cells: A double-edged sword targeting both apoptotic and autophagic machineries. Autophagy 9: 697-713, 2013.

22. Lin CH, Li CH, Liao PL, Tse LS, Huang WK, Cheng HW and Cheng YW: Silibinin inhibits VEGF secretion and age-related macular degeneration in a hypoxia-dependent manner through the PI-3 kinase/akt/mTOR pathway. Br J Pharmacol 168: 920-931, 2013.

23. Han S, Zhang G, Li M, Chen D, Wang Y, Ye W and Ji Z: L-securinine induces apoptosis in the human promyelocytic leukemia cell line HL-60 and influences the expression of genes involved in the PI3K/AKT/mTOR signaling pathway. Oncol Rep 31: 2245-2251, 2014.

24. Liu X, Wang L, Chen J, Ling Q, Wang H, Li S, Li L, Yang S, Xia M and Jing L: Estrogen receptor $\beta$ agonist enhances temozolomide sensitivity of glioma cells by inhibiting PI3K/AKT/mTOR pathway. Mol Med Rep 11: 1516-1522, 2015.

25. Wang C, Wang Z, Zhang X, Zhang X, Dong L, Xing Y, Li Y, Liu Z, Chen L, Qiao H, et al: Protection by silibinin against experimental ischemic stroke: Up-regulated pAkt, pmTOR, HIF-1 $\alpha$ and Bcl-2, down-regulated Bax, NF- $\mathrm{kB}$ expression. Neurosci Lett 529: 45-50, 2012. 